\title{
Long-Term Overgrazing-Induced Memory Decreases Photosynthesis of Clonal Offspring in a Perennial Grassland Plant
}

Weibo Ren ${ }^{1+}$, Ningning Hu${ }^{1+}$, Xiangyang Hou' ${ }^{*}$, Jize Zhang ${ }^{1}$, Huiqin Guo ${ }^{2}$, Zhiying Liu ${ }^{3}$, Lingqi Kong ${ }^{1}$, Zinian Wu ${ }^{1}$, Hui Wang ${ }^{1}$ and Xiliang $L^{1{ }^{1 *}}$

' Key Laboratory of Grassland Ecology and Restoration of Ministry of Agriculture, National Forage Improvement Center, Institute of Grassland Research, Chinese Academy of Agricultural Sciences, Hohhot, China, ${ }^{2}$ College of Life Sciences, Inner Mongolia Agricultural University, Hohhot, China, ${ }^{3}$ College of Ecology and Environment, Inner Mongolia University, Hohhot, China

OPEN ACCESS

Edited by: Urs Feller,

University of Bern, Switzerland

Reviewed by: Amarendra Narayan Misra, Central University of Jharkhand, India Annette Morvan-Bertrand, University of Caen Normandy, France

*Correspondence: Xiliang L igrlxl@caas.cn

Xiangyang Hou houxy16@vip.126.com

tThese authors have contributed equally to this work.

Specialty section:

This article was submitted to Agroecology and Land Use Systems, a section of the journal Frontiers in Plant Science

Received: 06 December 2016 Accepted: 10 March 2017 Published: 24 April 2017

Citation:

Ren W, Hu N, Hou X, Zhang J, Guo H, Liu Z, Kong L, Wu Z, Wang $H$ and Li $X$ (2017) Long-Term Overgrazing-Induced Memory Decreases Photosynthesis of Clonal Offspring in a Perennial Grassland Plant. Front. Plant Sci. 8:419. doi: 10.3389/fpls.2017.00419
Previous studies of transgenerational plasticity have demonstrated that long-term overgrazing experienced by Leymus chinensis, an ecologically dominant, rhizomatous grass species in eastern Eurasian temperate grassland, significantly affects its clonal growth in subsequent generations. However, there is a dearth of information on the reasons underlying this overgrazing-induced memory effect in plant morphological plasticity. We characterized the relationship between a dwarf phenotype and photosynthesis function decline of $L$. chinensis from the perspective of leaf photosynthesis by using both field measurement and rhizome buds culture cultivated in a greenhouse. Leaf photosynthetic functions (net photosynthetic rate, stomatal conductance, intercellular carbon dioxide concentration, and transpiration rate) were significantly decreased in smaller $L$. chinensis individuals that were induced to have a dwarf phenotype by being heavily grazed in the field. This decreased photosynthetic function was maintained a generation after greenhouse tests in which grazing was excluded. Both the response of $L$. chinensis morphological traits and photosynthetic functions in greenhouse were deceased relative to those in the field experiment. Further, there were significant decreases in leaf chlorophyll content and Rubisco enzyme activities of leaves between bud-cultured dwarf and non-dwarf $L$. chinensis in the greenhouse. Moreover, gene expression patterns showed that the bud-cultured dwarf L. chinensis significantly down-regulated (by 1.86- to 5.33-fold) a series of key genes that regulate photosynthetic efficiency, stomata opening, and chloroplast development compared with the non-dwarf $L$. chinensis. This is among the first studies revealing a linkage between long-term overgrazing affecting the transgenerational morphological plasticity of clonal plants and physiologically adaptive photosynthesis function. Overall, clonal transgenerational effects in L. chinensis phenotypic traits heavily involve photosynthetic plasticity.

Keywords: phenotypic plasticity, transgenerational effect, photosynthesis, grassland, livestock grazing 


\section{INTRODUCTION}

Ecologists have long been interested in phenotypic plasticity and its role in many ecological and evolutionary biological processes (Turcotte and Levine, 2016). The widely accepted definition of phenotypic plasticity is the performance of multiple phenotypes from a single plant genotype, in a manner dependent on environmental stimuli (Anderson et al., 2012). Theory predicts that greater phenotypic plasticity can result from the morphological, physiological, and phenological adaptive capacities in which plants can adjust their growing performances under various environmental variations (Kooke et al., 2015; Li X. et al., 2016).

Several studies have also reported that phenotypic changes could be observed over several generations in some cases (Mcintyre and Strauss, 2014). This ecological phenomenon is defined as transgenerational plasticity (Agrawal, 2002; Vu et al., 2015). Through this process, variation in environmental factors in the maternal generation, such as light, nutrients, water, pathogenic bacteria, and livestock grazing, influence the growth performance, life history, and biomass allocation of the progeny plants (Galloway and Etterson, 2007; Herman and Sultan, 2016). Recent progress in transgenerational plasticity research has experimentally demonstrated that local phenotypic adjustments under multiple stresses can transfer to the subsequent generation asexually under both uniform and contrasting environments in clonal plants (Latzel and Klimesova, 2010a; Gonzalez et al., 2016).

Similarly, natural grassland plants in are constantly subjected to various biotic and abiotic stresses as their habitats change seasonally and over time (Couso and Fernandez, 2012). A growing body of experimental evidence suggests that grassland plants show rapid phenotypic plasticity when exposed to such biotic and abiotic stresses ( $\mathrm{Li}$ et al., 2015a). For example, Couso and Fernandez (2012) reported that the most tolerant species had the highest morphological plasticity in an underlying trait in three Patagonian steppe grasses. In addition, previous studies have shown that light availability experienced by plant significantly influences the ability of following generations to respond to shade (Heger, 2016).

Typical steppe grasslands in Inner Mongolia, China, which are mainly dominated by Leymus chinensis, cover a large area of the eastern Eurasian temperate grassland (Schönbach et al., 2009). L. chinensis is a native, perennial, rhizomatous grass with high palatability and forage value; it is one of the most preferred species for large herbivores (Liu and Han, 2008; Huang et al., 2015). Therefore, it sustains higher relative levels of grazing by large herbivorous (Wang et al., 2010). Given the low genetic variation of clonal plants across a wide range of habitats, phenotypic plasticity can serve as the primary adaptive strategy, thereby allowing them to thrive in many grasslands (Aalto et al., 2014; Latzel et al., 2016; Liu Y. et al., 2016). Using large-scale field sampling and controlled watering experiments, Liu Y. et al. (2016) found that phenotypic plasticity in water use efficiency was more important than local adaptation in allowing the clonal L. chinensis to occupy a wide range of grassland habitats.

Understanding the biological processes of plant phenotypic plasticity in response to livestock grazing can provide insight into the process of grazing-induced changes in grassland ecosystem functioning. Our previous research on clonal transgenerational plasticity in grassland plant indicated that the significant response of morphological plasticity in L. chinensis with and without long-term overgrazing was maintained in the clonal offspring in a hydroponic experiment designed to remove the maternal environment (Li et al., 2015b). Importantly, leaf photosynthesis is the primary factor determining the carbohydrate sources of plant growth and development (Ellsworth et al., 2004). A growing body of empirical evidence from grazing ecosystems suggests that overgrazing by livestock may dramatically restrict leaf photosynthetic capacity in field conditions (Shen et al., 2013). However, there is a dearth of information on the linkages between plant morphological plasticity and leaf photosynthesis plasticity induced by livestock grazing.

In the present study, we used a long-term grazing and grazingexclusion field experiment to evaluate the effects of grazing on plant morphological and photosynthesis plasticity in L. chinensis. In particular, we investigated the memory effect of photosynthesis function by culturing rhizome buds to examine the underlying reasons in physiology, ultrastructure, and gene expression. We addressed three main research questions. (i) Is there an effect of grazing on plant performance of rhizome-cultured L. chinensis? (ii) What is the relationship between the memory effect of plant morphological plasticity and changes in photosynthetic characteristics? (iii) How is the transgenerational memory effect in photosynthetic plasticity of L. chinensis regulated by physiological and molecular pathways?

\section{MATERIALS AND METHODS}

\section{Field Site and Plants}

We conducted our phenotypic plasticity field experiment at the Inner Mongolia Grassland Ecosystem Research Station (IMGERS, $43^{\circ} 38^{\prime} \mathrm{N}, 116^{\circ} 42^{\prime} \mathrm{E}$, Figure 1). The study site is located in the Xilin River catchment, China at an altitude of approximately $1,200 \mathrm{~m}$ above sea level. The semiarid continental climate is characterized by a mean annual (1982-2008) temperature of $0.7^{\circ} \mathrm{C}$ and a mean annual precipitation of $335 \mathrm{~mm}$ (Supplementary Figure S1). Owing to inter-annual variability, the coefficient of variation of precipitation is $22 \%$ ( $\mathrm{Li}$ et al., 2015a). At our field site, the highest temperature coincides with the maximum precipitation in June, July, and August each year. For perennial plants, the growing season lasts for approximately 150 days from April/May to September/October, whereas annual plants germinate later, typically in July following the period of highest rainfall. The perennial rhizome grass L. chinensis and bunch grass Stipa grandis dominate the typical steppe communities of our study site (Li X. et al., 2016). And calcic kastanozem and calcic chernozems are the major soil types of this area. In this study, we selected $L$. chinensis as the model species for examining phenotypic plasticity in response to longterm overgrazing in the experiments. L. chinensis, dominates the Inner Mongolia grasslands, is widespread from the southern Chinese Loess plateau to the northern Russian Baikal and from the Sanjiang plain of eastern China to Ulan Bator in Mongolia 


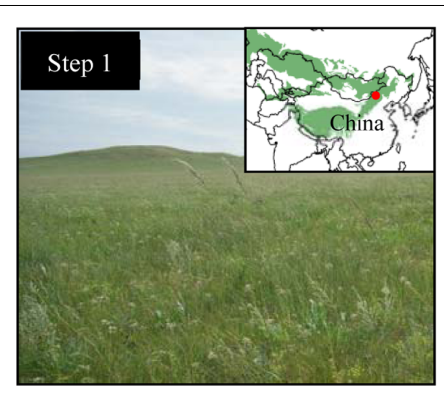

Before 1983

Native grassland

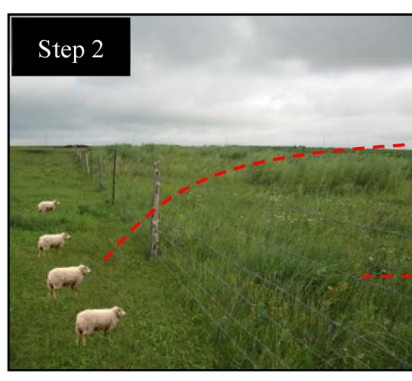

1983-2014

Field grazing experiments

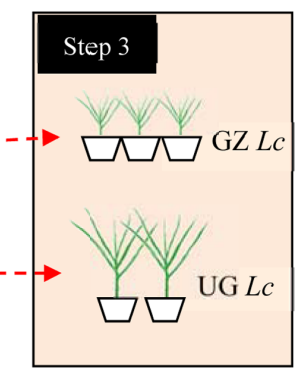

April-August 2015

Greenhouse experiments

FIGURE 1 | Scheme and schedule of the experimental design. The green area in the inlaid partial map of Asia shows the distribution of natural grassland, and the red dot represents our study area. GZ Lc, clone offspring of Leymus chinensis from long-term overgrazed grassland; UG $L c$, clone offspring of $L$. chinensis from ungrazed grassland.

(Liu Y. et al., 2016). In addition, L. chinensis is a rhizomatous native perennial plant with good palatability and high forage value. It is highly adaptable across grazed grassland ecosystems (Li et al., 2015b).

\section{Field Experiment}

The experimental design employed in the current study was previously described by Li et al. (2015b). Nearby long-term freely grazing and grazing-exclusion (ungrazed) plots were established in the study area. The grazing exclusion plot has been protected from grazers by a fence since 1983 by IMGERS for the purpose of long-term ecological observation and research. The grazing plot, of more than 200 ha in area, was situated adjacent to the grazing-exclusion plot and grazed by more than 600 sheep and goats year round over the last several decades ( $>30$ years; Li et al., $2015 b)$. In the two groups plots (i.e., grazed and ungrazed), three secondary plots were set, respectively. Five $1 \mathrm{~m} \times 1 \mathrm{~m}$ quadrats were randomly selected in each of the secondary plots. On the grazed plots, temporary movable ex-closure cages were set up at each sampling quadrat prior to grazing before the growing season in early April, 2014. The field sampling was carried out during 10-20 August 2014, corresponding to the annual peak-standing biomass (Supplementary Figure S1).

\section{Greenhouse Experiment}

Soil culture methods were employed in our greenhouse experiment. Before the start of the L. chinensis growing season, rhizome buds that had been at the same initial development state in the two experimental groups (grazed and ungrazed) were collected, respectively, in April 2015. In the laboratory, samples were clipped into 2 -cm lengths, and the rhizome buds of $L$. chinensis were cultivated in flowerpots, $30 \mathrm{~cm}$ in diameter and $25 \mathrm{~cm}$ high, in the same resource environment to remove the impact of nutrition, water, illumination, etc., in long-term overgrazing plots. Vermiculite and nutritional soil (1:2 ratio) were well mixing in each flowerpot, and each was planted with five rhizome buds. Six flowerpots planted with L. chinensis rhizomes were cultivated for each treatment. In total, these 12 flowerpots were randomly arranged in the greenhouse (at $25^{\circ} \mathrm{C}$ under light and $15^{\circ} \mathrm{C}$ under dark cycles with natural light and regular watering), which was located at Institute of Grassland Research, Chinese Academy of Agricultural Sciences, Hohhot, Inner Mongolia, China.

\section{Measurements \\ Morphological Traits}

We measured morphological, physiological, and molecular properties of $L$. chinensis leaves at the rapid and peaking growth period in the field (early August) and laboratory (45 days after seedling establishment). The phenotypic traits we measured in L. chinensis were plant height, leaf length, leaf width, stem length, and stem diameter. The measuring methods employed in the current study were described in a previous publication (Li et al., 2015a). Both in the field and greenhouse experiment, leaf length and leaf width were measured from the second leaf from the bottom of each plant, which is the youngest mature leaf of each individual. The stem diameter was measured at the second internode from the bottom of L. chinensis stems. First, in the field experiment, three L. chinensis individuals were selected randomly in each $1 \mathrm{~m} \times 1 \mathrm{~m}$ quadrat. Phenotypic traits of $L$. chinensis were measured in a darkened laboratory room after the whole aboveground portion of plant individuals were clipped completely in the field. As in our field experiment, after 45 days of cultivation, the same phenotypic traits of the mature L. chinensis plants were measured from all 12 of the flowerpots in our greenhouse testing using the same methods and indexes. These measurements were taken from three L. chinensis selected randomly from each flowerpot.

\section{Photosynthetic Capability}

At the same time morphological traits were measured, photosynthetic capability was measured from the second leaf from the bottom of each L. chinensis plant both in the field and greenhouse experiment. Net photosynthetic rate $\left(P_{N}\right)$, stomatal conductance $(g s)$, intercellular carbon dioxide concentration $\left(C_{i}\right)$, and transpiration rate $(E)$ were determined using a portable open flow gas exchange system LI-6400XT 
(LI-COR, Lincoln, NE, USA) at 2-h intervals from 9:00 to 11:00 $\mathrm{h}$ in the field. Intrinsic water use efficiency (WUE) was calculated as $P N / E$. Photosynthetically active radiation $(P A R)$ was $1000 \pm 10 \mu \mathrm{mol} \mathrm{m}^{-2} \mathrm{~s}^{-1}, \mathrm{CO}_{2}$ concentration was $350 \pm 3 \mathrm{ppm}$, and leaf temperature was $27.0 \pm 1.1^{\circ} \mathrm{C}$ (Reich et al., 2003; Li et al., 2014).

\section{Chlorophyll Content}

The content levels of chlorophyll $\mathrm{a}$ and $\mathrm{b}$ were measured using UV spectrophotometry (Laureau et al., 2013). Leaf tissues $(5 \mathrm{~g})$ were placed into test tubes, extracted with $30 \mathrm{ml}$ of DMSO, and incubated overnight at $70^{\circ} \mathrm{C}$. Chlorophyll contents were calculated at 665 and $649 \mathrm{~nm}$ by a spectrophotometer. Chlorophyll contents were expressed as $\mathrm{mg} / \mathrm{g}$ fresh weight.

\section{Chloroplast Ultrastructure}

For the ultrastructural analysis, we examined samples of L. chinensis leaves that were grazed or ungrazed using a rhizome bud culture method in the greenhouse, with samples from corresponding sampling dates measured for each morphological and physiological measurement. For each treatment we used three L. chinensis leaves. The samples were fixed in $2.5 \%$ glutaraldehyde solution in $0.1 \mathrm{M}$ phosphate buffer ( $\mathrm{pH} 7.3$ ) for $24 \mathrm{~h}$ at $5^{\circ} \mathrm{C}$, post-fixed with $1 \%$ osmium tetroxide in the same buffer for $1 \mathrm{~h}$ at $25^{\circ} \mathrm{C}$, dehydrated through an acetone series, and embedded in Araldite resin. Ultra-thin sections were obtained with a DiATOME diamond knife (DiATOME, Hatfield, PA, USA) and post-stained with uranyl acetate and lead citrate (Reynolds, 1963). The material was examined in an FEI Tecnai ${ }^{\text {TM }}$ transmission electron microscope (FEI, Hillsboro, OR, USA) at $80 \mathrm{kV}$.

\section{Rubisco Enzyme Activity}

In our measurement, $0.5 \mathrm{~g}$ leaf sample was rapidly ground in a 15-mL tube with liquid $\mathrm{N}_{2}$. Then spectrophotometry and Rubisco Activase Assay Kit was used to determine the enzyme activity according to a procedure in literature (Bernacchi et al., 2005; Li X.-J. et al., 2016).

\section{Gene Expression}

At the same time, leaves samples of $L$. chinensis were collected from the two greenhouse experimental groups (clonal offspring grazing and ungrazing $L$. chinensis). Leaf material that was snap frozen and stored at $-80^{\circ} \mathrm{C}$ was after being ground to a fine powder in liquid $\mathrm{N}_{2}$ with a mortar and pestle (Liu Z.-Y. et al., 2016). The potential roles of the 12 studied genes, which is previously identified as having a role in plant photosynthesis (Boonman et al., 2009), has been preliminarily confirmed by our transcriptome data (Supplementary Table S1).

Total RNA was extracted from the L. chinensis leaves with TRIzol Reagent (Invitrogen, Carlsbad, CA, USA). Total RNA from each sample was reverse transcribed using Prime Script ${ }^{\text {TM }}$ RT reagent kit with gDNA Eraser (Perfect Real Time; Clontech, Mountain View, CA, USA) and stored at $-20^{\circ} \mathrm{C}$ (Supplementary Figure S2). Primers used for gene amplification are listed in Supplementary Table S1. Primers were designed for a reference gene Actin1 (GenBank accession number,
HM623326.1). Primers were designed using the online primer design software PerlPrimer v.1.1.21.

The method of quantitative real-time PCR has been described by previous studies (Livak and Schmittgen, 2001; Liu Z.-Y. et al., 2016). Therefore, we briefly describe the experimental process in this paper. Quantitative real-time PCR was carried out in an iQ5 Optical System (Bio-Rad, Hercules, CA, USA) using the SYBR Premix Ex Taq Kit (TaKaRa Biomedical, Shiga, Japan; Liu Z.-Y. et al., 2016). The relative expression level was calculated using the comparative $\mathrm{C}(\mathrm{t})$ method (which notes the PCR cycle at which the fluorescent signal of the reporter dye crosses an arbitrary threshold; Supplementary Figure S3; Peng et al., 2011; Liu Z.-Y. et al., 2016).

\section{Statistical Analysis}

Before all of the statistical analyses were conducted, the phenotypic traits were averaged from three $L$. chinensis individuals in one quadrat in the field experiment or individual flowerpot in the greenhouse experiment (Li et al., 2015a; Li $X$. et al., 2016). The relative concentration of each gene of interest from the qRT-PCR analysis was log-transformed before analysis. Significant differences in each index, including plant phenotypic traits, photosynthetic characteristics, chlorophyll content, Rubisco enzymatic activity, and gene expression quantities, between the ungrazed and grazed groups were evaluated by Student's $t$-test. The responses of phenotypic traits and photosynthetic characteristics were calculated by Ln(control/grazed; (Zheng et al., 2012). Linear correlations in this research were analyzed by the Pearson method. The non-linear relationship between $g s$ and $P_{N}$ was fitted with an equation describing exponential rise to a maximum $\left(y=y_{0}+a\left(1-e^{-\mathrm{bx}}\right)\right)$. All statistical analyses were performed to determine the significance of treatment means at $P<0.05$ and $P<0.01$ significance levels using SPSS 19.0 statistical software (SPSS, Inc., Chicago, IL, USA).

\section{RESULTS}

Long-term overgrazing significantly decreased the plant size of L. chinensis individuals, including plant height, leaf length, leaf width, stem length, and stem diameter $(P<0.01$, Figure 2$)$. Moreover, we observed significant responses in morphological plasticity between the grazed and ungrazed treatments were maintained in the greenhouse experiments that were designed to remove environmental variability by the bud culture method $(P<0.05$, Figure 2).

Under grazing, photosynthetic functions, such as $P_{N}, g s$, $C \mathrm{i}$, and $E$, were significantly decreased in a manner that corresponded with the dwarf phenotype of $L$. chinensis individuals in field conditions $(P<0.01)$. In contrast, WUE was not affected by grazing $(P>0.05$, Figure 2$)$. This decreased photosynthetic function was maintained after one generation of grazing exclusion in greenhouse tests (Figure 3). Moreover, $P_{N}$ values were significantly correlated with $C i$ and $E$ not only in the field but also in greenhouse tests (Table 1) and especially correlated with gs (Figure 4). 

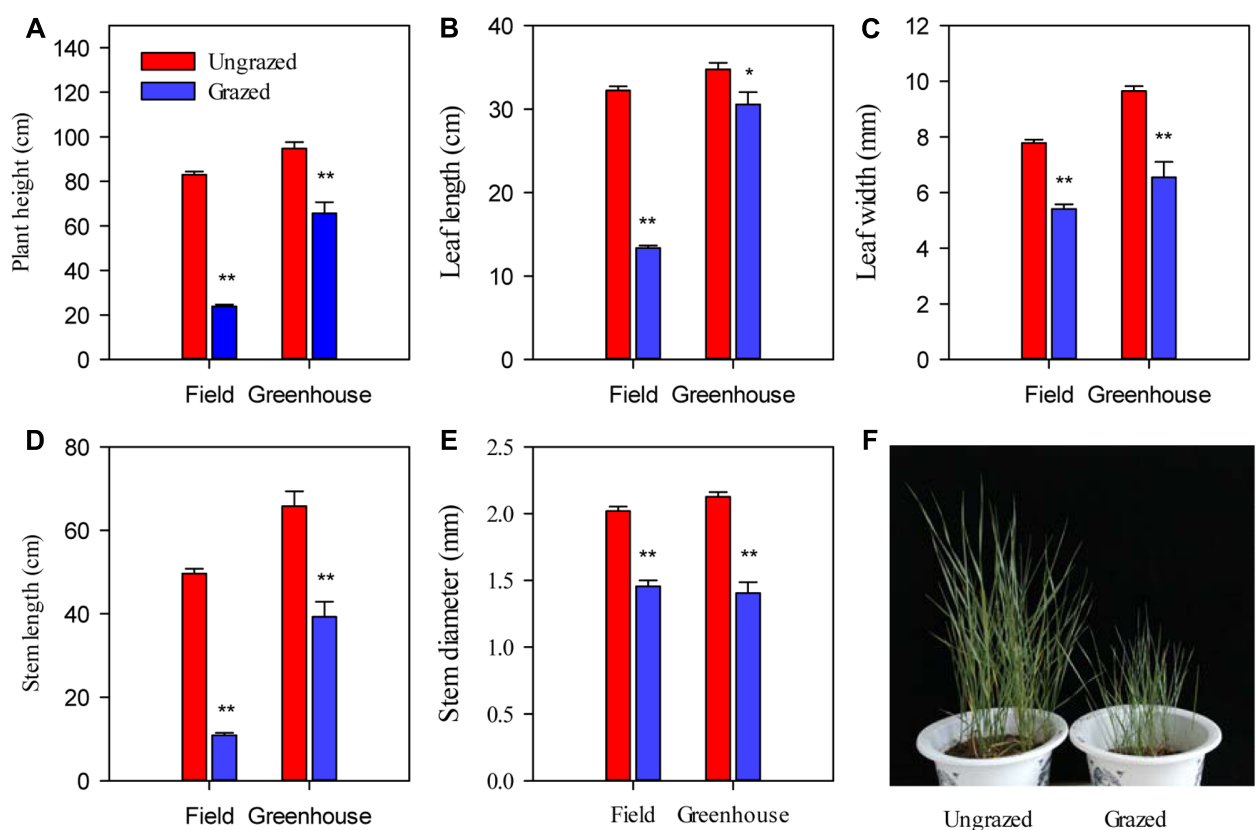

FIGURE 2 | Differences in plant growth and various morphological traits in Leymus chinensis in response to previous generation grazing in field and greenhouse conditions. (A-E) The morphological traits indicated on the $x$-axis. (F) Photographs of bud culture $L$. chinensis in the greenhouse. The cultured L. chinensis buds were collected from the field, specifically the long-term overgrazing and grazing exclusion grasslands. Symbols: ${ }^{* *} P<0.01 ;{ }^{*} P<0.05$.

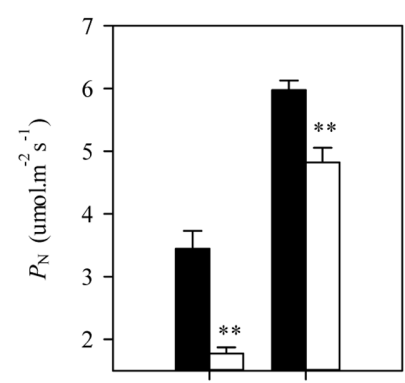

Field Greenhouse

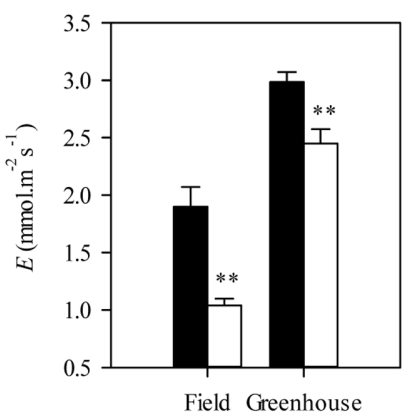

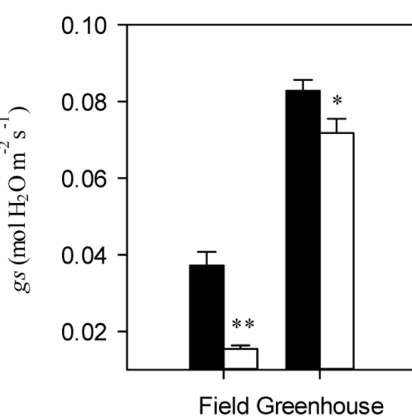
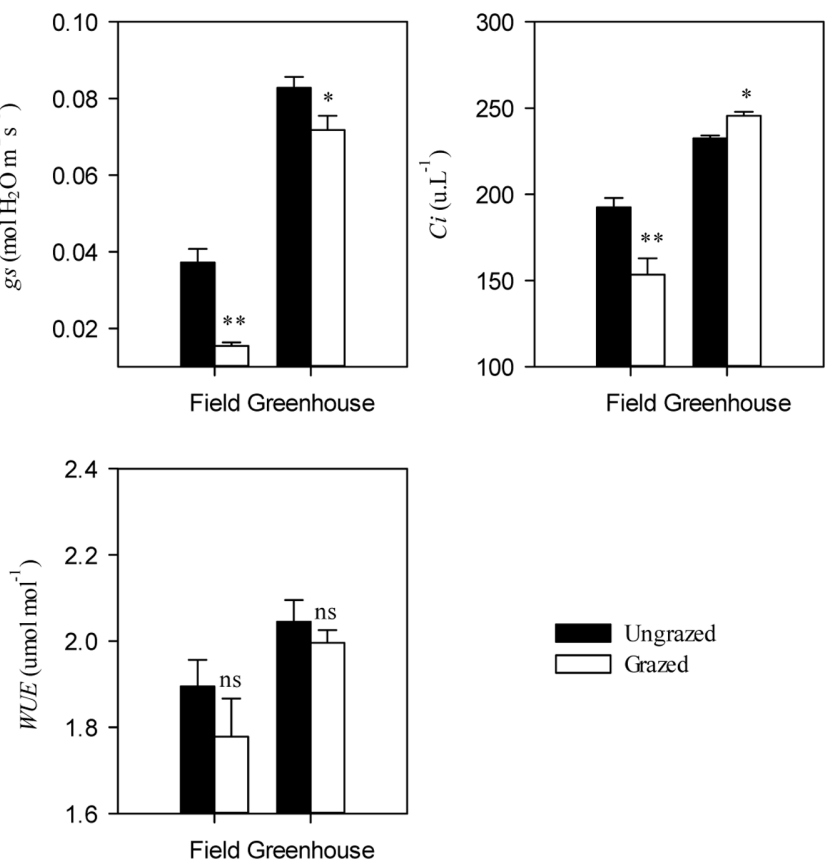

Ungrazed

Grazed

FIGURE 3 | Effects of grazing on leaf photosynthetic traits in Leymus chinensis under field and greenhouse experiments. $P_{N}$, Net photosynthetic rate; gs, Stomatal conductance; $\mathrm{Ci}$, Intercellular carbon dioxide concentration; $\mathrm{E}$, Transpiration rate; and WUE, water use efficiency. Symbols: ${ }^{* *} P<0.01$; ${ }^{*} P<0.05$; ns, $P>0.05$.

Notably, the responses of $L$. chinensis morphological traits to grazing in the greenhouse were markedly deceased relative to the field experiment (by $33.91 \% \sim 59.83 \%$, Figure 5A). Similar to our finding in morphological traits, the responses of $P_{N}, g \mathrm{~s}$, $C \mathrm{i}$, and $E$ of the grazed treatment in the greenhouse experiment were weakened compared to those in the field observations (by 
TABLE 1 | Correlations among photosynthetic characteristics of Leymus chinensis leaf in field and greenhouse conditions.

\begin{tabular}{|c|c|c|c|c|}
\hline \multirow{2}{*}{$\begin{array}{l}\text { Photosynthetic } \\
\text { characteristics }\end{array}$} & \multicolumn{2}{|c|}{ Field } & \multicolumn{2}{|c|}{ Common garden } \\
\hline & $r$ & significance & $r$ & Significance \\
\hline$P_{N}-g s$ & 0.95 & $* *$ & 0.92 & $* *$ \\
\hline$P_{N}-C i$ & 0.16 & ns & -0.20 & $*$ \\
\hline$P_{N}-E$ & 0.95 & $* *$ & 0.90 & $* *$ \\
\hline$P_{N}-W U E$ & 0.08 & ns & 0.13 & ns \\
\hline$g s-C i$ & 0.39 & ** & 0.19 & * \\
\hline$g s-E$ & 0.99 & $* *$ & 0.90 & $* *$ \\
\hline gs-WUE & -0.15 & ns & -0.06 & ns \\
\hline$C i-E$ & 0.37 & $* *$ & -0.06 & ns \\
\hline$C \mathrm{i}-W U E$ & -0.84 & $* *$ & -0.37 & $* *$ \\
\hline$E-W U E$ & -0.19 & ns & -0.30 & $* *$ \\
\hline
\end{tabular}

$P_{N}$, Net photosynthetic rate; gs, Stomatal conductance; $\mathrm{Ci}$, Intercellular carbon dioxide concentration; E, Transpiration rate; and WUE, water use efficiency. ${ }^{* *} P<0.01 ; * P<0.05 ; n s, P>0.05$

41.67\% 92.78\%, Figure 5B). There had positive correlations between the responses ratios in field and greenhouse both of L. chinensis morphological traits $\left(R^{2}=0.47, P=0.20\right)$ and photosynthetic traits $\left(R^{2}=0.98, P<0.001\right.$, Figure 5).

Furthermore, we detected that long-term overgrazing significantly decreased the contents of chlorophyll a and chlorophyll b in $L$. chinensis leaves $(P<0.05$, Figure 6A). After one generation of exclusion from grazing via the rhizome bud culture method, we also detected a significant difference in chlorophyll contents of leaves between dwarf and non-dwarf

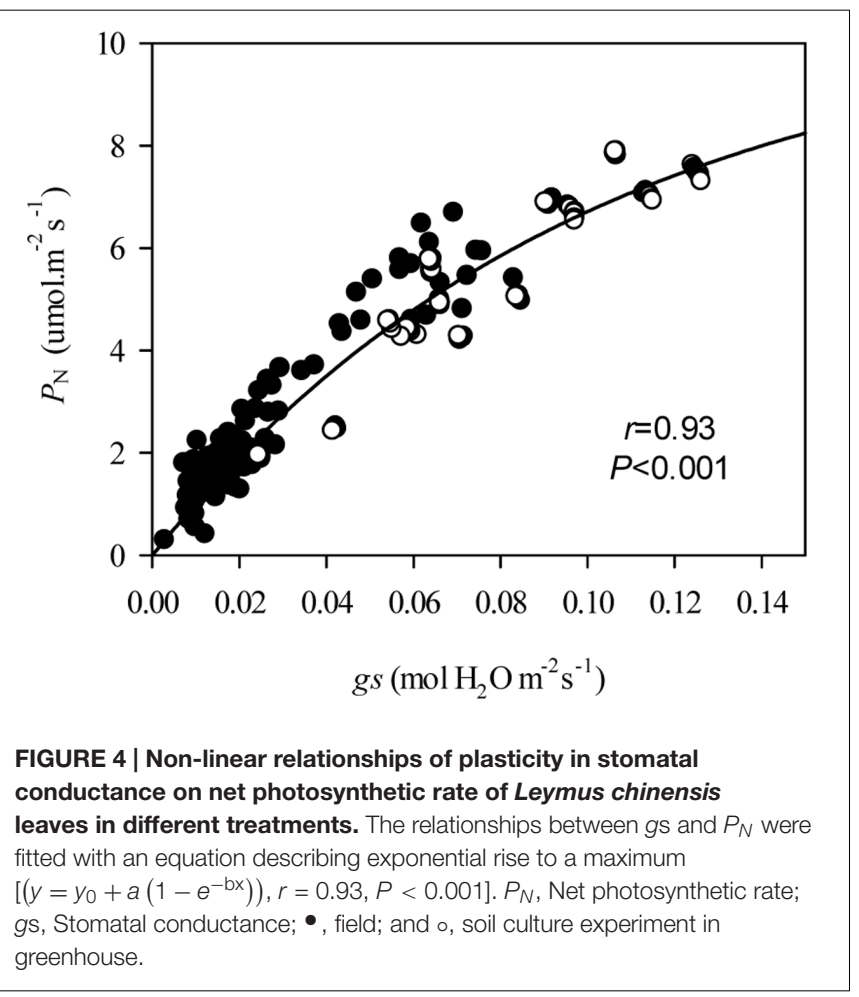

L. chinensis $(P<0.05$, Figure 6B). Moreover, there were obvious changes in chloroplast ultrastructure of plants derived from grazing-stressed materials in the greenhouse experiment (Figure 7). Specifically, our results showed that the cells became smaller and chloroplast numbers per cell diminished, while the grana lamella concentration and osmiophilic granules increased (Figure 7). In addition, we found that the transgenerational memory effect of grazing-induced plant dwarf phenotypes significantly decreased leaf Rubisco enzyme activities compared with those of the non-dwarf L. chinensis $(P<0.05$, Figure 8).

To unravel the linkages between the plant morphological plasticity and leaf photosynthesis plasticity induced by livestock grazing at molecular level, we analyzed the expression patterns of a series of key genes that regulate photosynthetic efficiency, chlorophyll synthesis, and chloroplast development (Supplementary Figure S2). We found that the expression levels of the genes (except $f d x 3$ ) in grazing-induced dwarf L. chinensis showed 1.86- to 5.33-fold decreases compared with those of the non-dwarf $L$. chinensis $(P<0.05$, Figure 9).

\section{DISCUSSION}

Phenotypic plasticity, ecotypic differentiation, and ecological speciation are three different gradations of adaptation to externally ecophenotypic variation (Rausher, 2005). In many ways, the evolution of phenotypic plasticity is the most basic mode of plant species evolution and adaptation (Anderson et al., 2012; Turcotte and Levine, 2016). In this study, we initially found that field long-term overgrazing significantly decreased the individual size of $L$. chinensis. In general, phenotypic plasticity is the ability of plants to modify their phenotype in response to environmental changes. Previous studies have shown that clonal plants, such as L. chinensis, physiologically, morphologically, and phenologically adapt to different levels of resource availability and various kinds of environmental disturbances through phenotypic plasticity (Bai et al., 2009; Li X. et al., 2016).

Notably, our greenhouse experiments demonstrated that there was also a significant difference in plant height of $L$. chinensis between rhizome bud-cultured plants that were derived from field samples that did or did not experience grazing. Recently, an increasing number of case studies have reported that parent plants can transmit their performances in phenotypic plasticity responses as some kind of ecophenotypic variation to their offspring by seed or clonal propagation (Galloway and Etterson, 2007; Latzel et al., 2016). Our demonstration of the memory effect of the dwarf phenotype of $L$. chinensis as an adaptation to long-term overgrazing provides new evidence for clonal transgenerational memory in clonal plants. We speculate that the maintenance of phenotypic characteristic in clonal propagation may function as a grazing-avoidance for grassland plants that have adapted to grazing (N'guessan and Hartnett, 2011). Longterm overgrazing appears to induce the clonal offspring to form a phenotype that matches the grazing-avoidance phenotype in order to prepare for possible grazing by large herbivores, which was often experienced by their ancestors. 

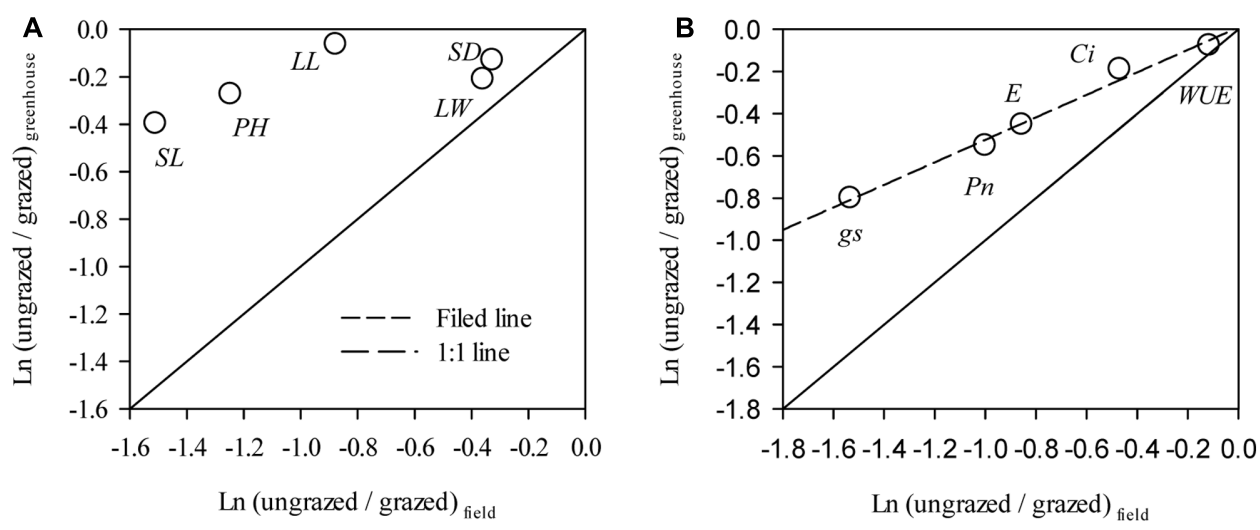

FIGURE 5 | Comparisons between response in Leymus chinensis (A) morphological traits and (B) leaf photosynthetic traits to overgrazing in field and greenhouse experiments. The relationships for morphological traits $\left(R^{2}=0.47, P=0.20\right)$ and leaf photosynthetic traits $\left(R^{2}=0.98, P<0.001\right)$ between the responds ratios of field and greenhouse experiments were fitted by linear regression. PH, Plant height; LL, Leaf length; LW, Leaf width; SL, Stem length; SD, stem diameter; $P_{N}$, Net photosynthetic rate; gs, Stomatal conductance; Ci, Intercellular carbon dioxide concentration; E, Transpiration rate; and WUE, water use efficiency. Data were log-transformed (base e) before analysis to improve normality.
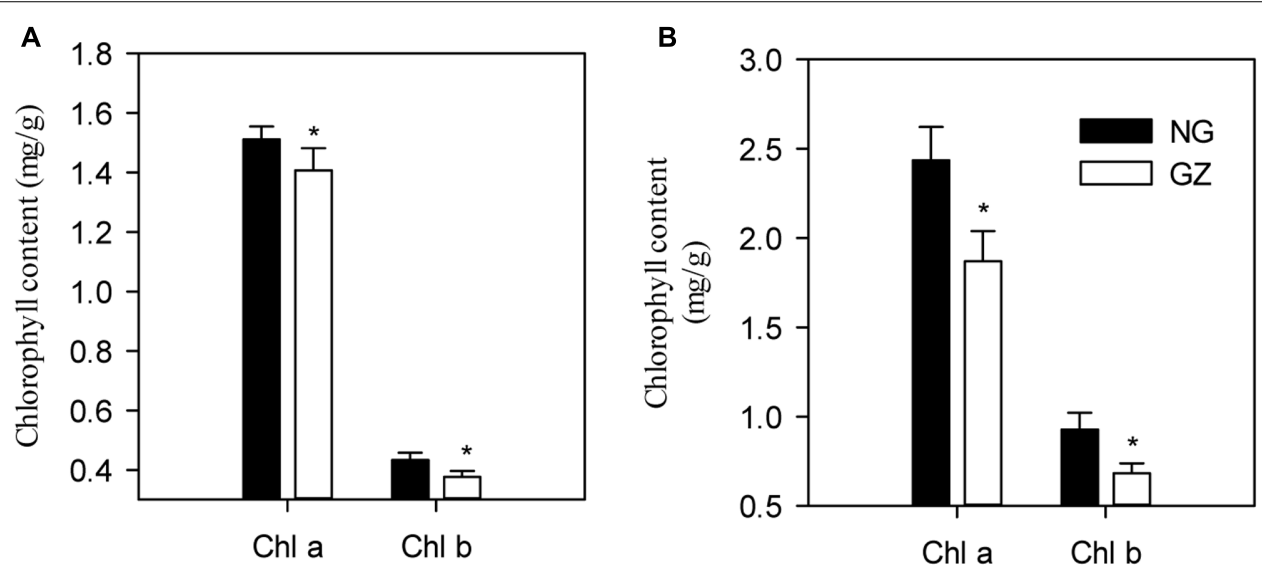

FIGURE 6 | Difference in leaf chlorophyll content for field-grown and bud-cultured Leymus chinensis in early growth stages under long-term overgrazing and grazing exclusion. (A) Chlorophyll a and chlorophyll b in the field condition. (B) Chlorophyll a and chlorophyll b in greenhouse condition. NG, ungrazed; GZ, grazed.

In addition, the results of this and previous studies imply that the clonal transgenerational memory of phenotype changes in the offspring may be restored in grazed grassland plants (Latzel and Klimesova, 2010b). Some restoration process research focusing on grassland degradation caused by overgrazing have reported that individual plants can return to normal conditions after several years of restoration effort (Li et al., 2008). However, the process of plasticity recovering to normal for maintained dwarf phenotype of $L$. chinensis warrants more detailed studies that utilize greenhouse experiments observed for several clonal generations. Also, more and more evidence of epigenetic inheritance in molecular biology has shown that histone variants, histone N-tail modifications, and DNA methylation affected the expression not only of within-generation phenotypic plasticity but also of transgenerational phenotypic plasticity (Iwasaki, 2015; Herman and Sultan, 2016; Wang et al., 2016). These previous empirical and theoretical studies have provided direct or indirect support for the type of phenotypic plasticity observed in L. chinensis in this study.

To reveal the possible reason for grazing-induced phenotypic plasticity, we detected the photosynthetic efficiency of L. chinensis leaves both in the field and greenhouse experiments. Long-term overgrazing significantly decreased leaf photosynthetic rates, in correspondence with the dwarf phenotype of L. chinensis individuals in grazed field conditions, which is consistent with previous studies across many grazing experiments conducted in semi-arid grasslands. Empirical studies focusing on the effect of grazing intensities on plant photosynthesis have indicated that defoliated plants can overcompensate for lost tissues by compensatory photosynthesis to a limited extent (Detling et al., 1979; Liu H. et al., 2016). In this study, however, long-term overgrazing restricted the compensatory effect of plant photosynthesis, which resulted in the dwarf phenotype of L. chinensis plants. Further evidence demonstrated 

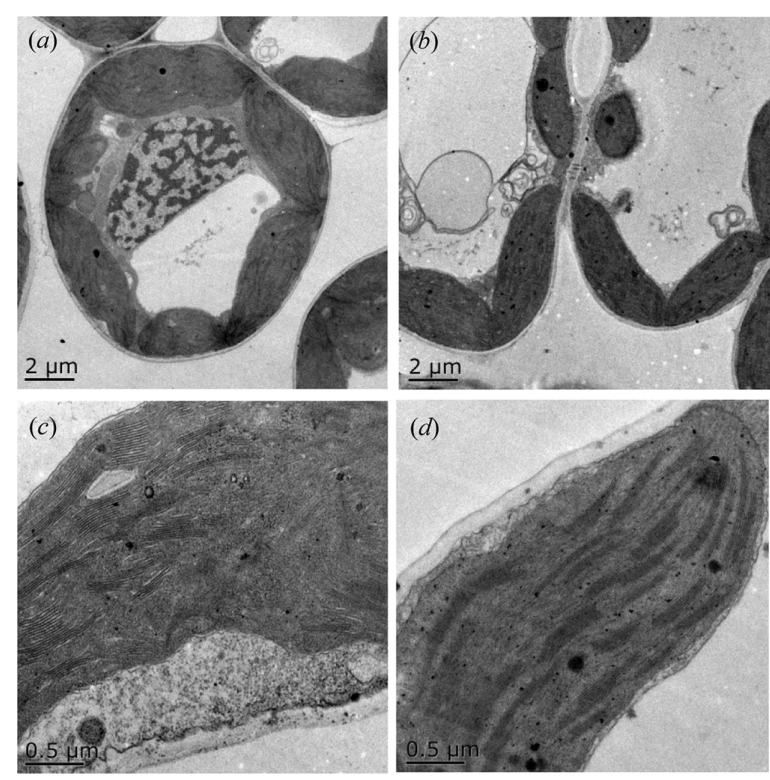

FIGURE 7 | Ultrastructure of chloroplast in ungrazed and grazed Leymus chinensis leaves grown from bud culture. $(\mathrm{a}, \mathrm{c})$ The morphological characteristics of the whole cell and chloroplast of ungrazed L. chinensis, shown with 2 and $0.5-\mu \mathrm{m}$ scale bars; (b,d) The morphological characteristics of the whole cell and chloroplast of grazed $L$. chinensis, shown with 2 and $0.5-\mu \mathrm{m}$ scale bars.

that overgrazing-induced declines in photosynthesis were coregulated by stomata size and chlorophyll content in field tests. Many studies that focused on the plant photosynthesis in response to biotic or abiotic disturbances support the results in this study to some extent (Zhao et al., 2009). Leaf photosynthetic plasticity, therefore, plays a key role in the adaptation of L. chinensis to long-term overgrazing through morphological plasticity.

In this research, furthermore, we found the decreases in photosynthetic functions were maintained after a generation of grazing exclusion in greenhouse experiments. These results could explain the maintenance of grazing-induced morphological plasticity of $L$. chinensis in the greenhouse experiments. Previously, we found a significant response in morphological plasticity under grazing was maintained in a hydroponic experiment designed to remove environmental variability, but there was no significant difference in L. chinensis individual size traits (Li et al., 2015b). In the current research, the memory effect of photosynthetic plasticity provides new information on clonal transgenerational adaptations for grazing avoidance. Moreover, there is no previous research establishing the mechanism underlying the memory effect of photosynthetic plasticity in plants that experience long-term overgrazing. We therefore posit that it is most likely associated with individual adaptive changes in the photosynthetic apparatus and hormone signaling in clonal plant species, consistent with previous studies (Whitehead et al., 2011).

The responses of morphological plasticity and photosynthetic plasticity to grazing showed that both the L. chinensis

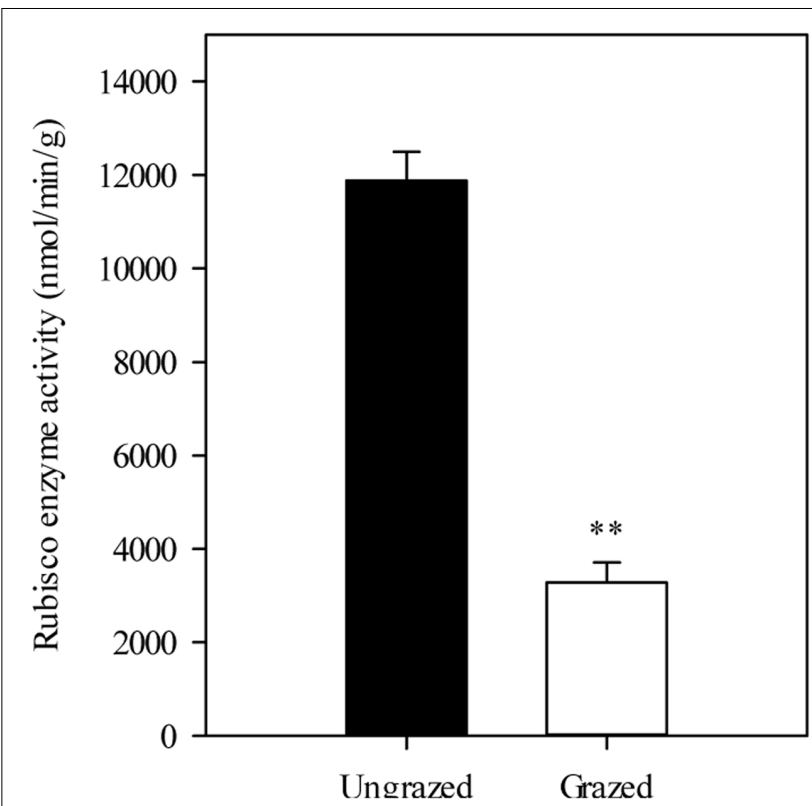

FIGURE 8 | Rubisco enzyme activities in ungrazed and grazed Leymus chinensis leaves grown from bud culture. ${ }^{* *} P<0.01$.

morphological and photosynthesis in the greenhouse were sharply deceased relative to those observed in the field tests. This suggests that grazed clones only partially maintained differences in phenotype and photosynthesis plasticity in the absence of stimuli such as livestock foraging and soil feedback. Hence, grazing-induced field morphological plasticity of plants can be divided two portions, i.e., transferable plasticity and nontransferable plasticity (von Caemmerer et al., 2004; Li et al., 2015b). This study suggests that the non-transferable plasticity is mediated by root tissue influenced by in soil bulk density, nutrient availability (Conant et al., 2001; Mcsherry and Ritchie, 2013).

It is important to detect the reasons for the clonal transgenerational effects of long-term grazed L. chinensis. At organelles level, we demonstrated that the adaptive changes in chloroplast development of clonal offspring of L. chinensis may lead to the reduction in photosynthesis directly. There were significant decreases in leaf chlorophyll contents and differences in chloroplast ultrastructure of leaves between the bud-cultured dwarf and non-dwarf L. chinensis plants in the greenhouse. Importantly, we detected a significant decrease in the expression of three previously putative chloroplast development genes (CLPB1, APK1B and APK1A) (Tanaka et al., 2000; Lee et al., 2007; Das et al., 2012), providing molecular evidence for developmentally limited of chloroplast in dwarf L. chinensis. Thus, the clonal transgenerational plasticity induced by grazing is possibly mediated by the adaptive changes in chloroplast development, which is supported by several previous studies (Reddy et al., 2002; Li et al., 2013). We posit that chloroplast development is a potential reason of dwarfism in L. chinensis limiting chlorophyll synthesis. 

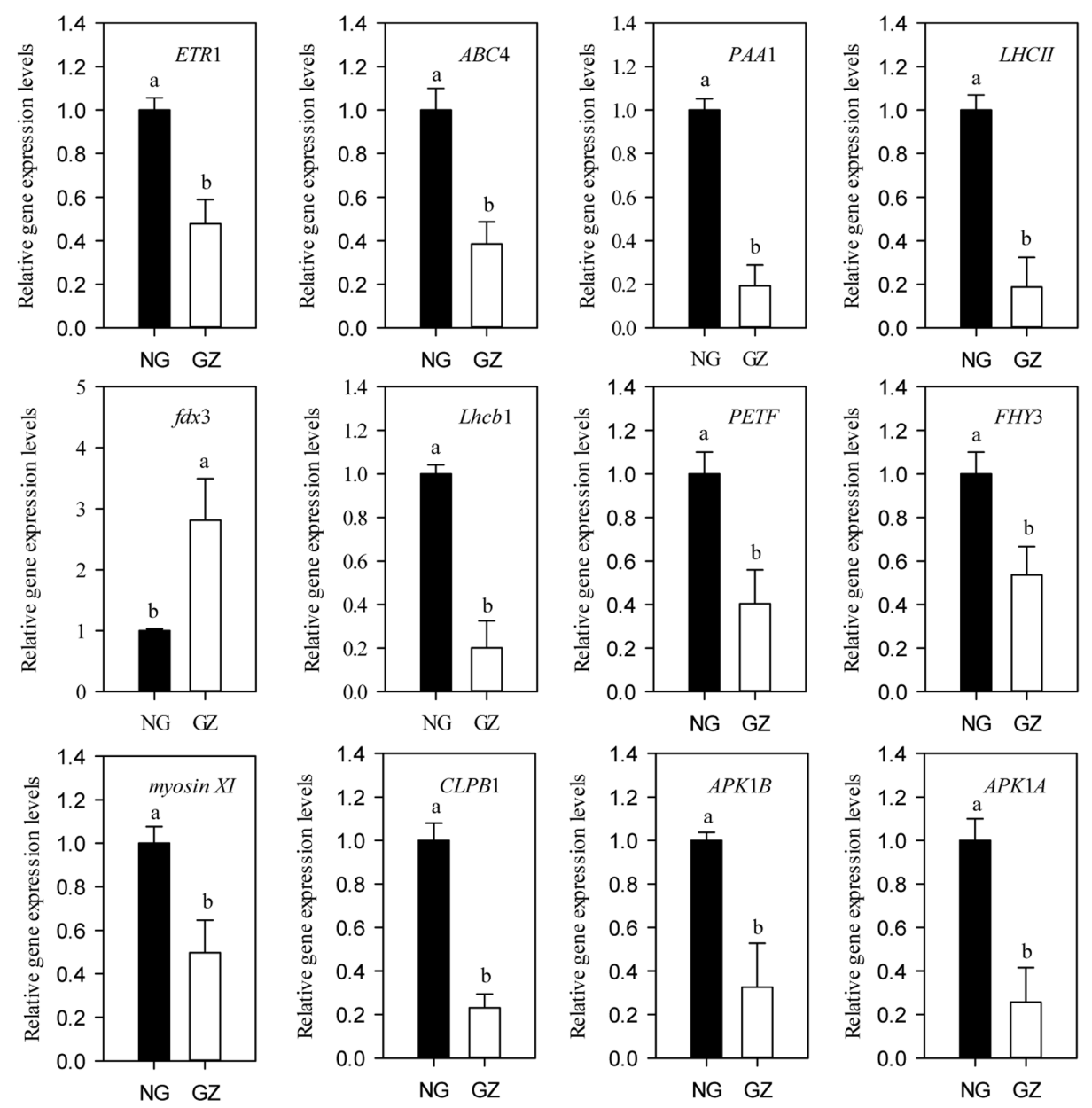

FIGURE 9 | Relative expression levels of genes related to photosynthesis from ungrazed and grazed Leymus chinensis leaves grown from bud culture. Error bars represent SEs. Differing letters indicate significant differences $(P<0.05$; $t$-test). NG, ungrazed; GZ, grazed.

In addition to the role of the changes in chloroplast, our results imply the limitation of stomatal traits may be associated with the observed transgenerational plasticity. Decreased stomatal conductance was the primary determinant of the photosynthetic rate in bud-cultured dwarf $L$. chinensis. The down-regulated expression of gene related to stomatal regulation, for example, ETR1, may have contributed to the adaptive changes in the photosynthesis. Previously, some studies had proved that the ETR1 gene played key roles in guard cell movement and stomata opening under multiple stresses (Desikan et al., 2005; Ge et al., 2015). In this research, we further speculate that smaller leaf stomata mediated by gene regulation may reduce the loss of water and improve plant fitness in grazing-induced dry habitats of semi-arid grasslands (Escalona et al., 1999; von Caemmerer et al., 2004). However, these potentially adaptive changes in stomatal traits decreased $L$. chinensis photosynthetic capacity significantly.

Moreover, we found decreasing efficiency in the light and dark reactions of photosynthesis may also be mediating the observed plasticity. It is likely that clonal transgenerational plasticity of plant photosynthetic capacity is subject to multiple photobiological processes in response to large herbivore grazing (Blankenship, 2002; Zhao et al., 2009). In addition to the role of photosynthetic organelles change, we propose that the observed phenomenon was also related to the changes in photosynthetic processes, such as light trapping and light energy transformation, and carbon assimilation. Seven of the eight assayed genes, mainly encoding pigment protein complex, showed significant decrease at transcript level between treatments, providing strong support for the process by which photosynthetic capacity decreases in L. chinensis clonal offspring.

In the light reaction process, we detected that there had significant decrease in the expressions of light harvesting genes (LHCII and Lhcbl for example) and photosynthetic electron transfer chain genes ( $f d x 3$ and PETF for example) (Teramoto et al., 2001; Pascal et al., 2005; Grudzinski et al., 2016). In the dark reaction process, the expressions of carbon assimilation genes, such as SR45 (Day et al., 2012), were significantly decreased in grazed L. chinensis clonal offspring. These results implied the photosynthetic function pathways, including the light and dark reactions, 


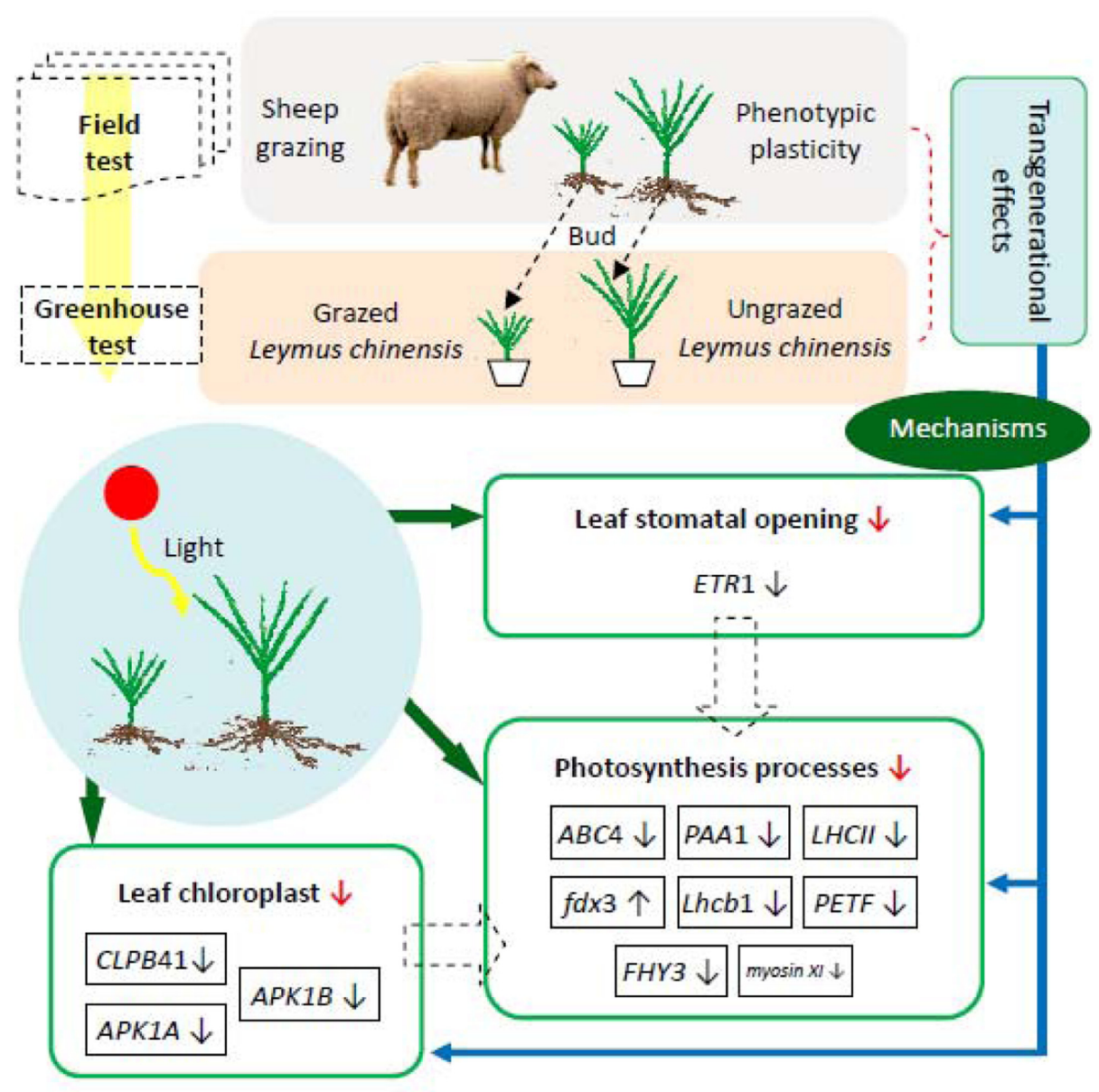

FIGURE 10 | Schematic diagram illustrating the linkages between morphological plasticity and leaf photosynthesis plasticity induced by long-term livestock overgrazing of Leymus chinensis. $\downarrow$ Significant decrease in photosynthesis-relevant processes; $\downarrow$ significant down-regulation of gene expression; $\uparrow$ significant up-regulation of gene expression.

each of which may cause decreases in photosynthesis among the clonal offspring of $L$. chinensis. At enzyme level, furthermore, previous studies have indicated that Rubisco enzymes were significantly correlated with photosynthesis (Demars et al., 2016), supporting our results that the transgenerational effect was closely associated with the decrease in Rubisco enzyme activities in grazed $L$. chinensis offspring.

In general, photosynthetic plasticity and morphological dwarfism in the clonal offspring of $L$. chinensis which experienced long-term overgrazing is an adaptation to avoid animal grazing. The field and greenhouse results characterizing morphological, physiological, and molecular responses of L. chinensis leaves to grazing are described in Figure 10, which contains schematic diagrams illustrating the linkages between the L. chinensis morphological plasticity and photosynthesis plasticity induced by long-term livestock overgrazing. In this figure, overgrazing-induced clonal transgenerational effect (morphological adaptation) is mediated by the adaptive changes in photosynthetic plasticity. Then under long-term grazing stress, the principal cause of the reduction in photosynthesis was attributed to the changes of structure of photosynthetic organelles (chloroplast and stomata) and function of photosynthetic processes (light and dark reactions).

\section{CONCLUSION}

This study is among the first to provide strong evidence that clonal transgenerational effects are linked to adaptive changes in photosynthetic physiology in a long-term grazed plant. Both in maternal plants in the field and clonal offspring in greenhouse, leaf photosynthesis were significantly decreased by grazing of the previous generation, corresponding with the dwarf phenotype of $L$. chinensis induced by grazing disturbance. Multiple reasons underlying the transgenerational plasticity of $L$. chinensis photosynthesis were observed in this study. There were significant decreases in leaf chlorophyll contents and Rubisco enzyme activities of grazed L. chinensis offspring 
compared with offspring of ungrazed L. chinensis. In addition, gene expression patterns in the bud cultured dwarf $L$. chinensis exhibited a significant down-regulation of a series of key genes that regulate photosynthetic efficiency, stomata opening, and chloroplast development compared with non-dwarf L. chinensis.

\section{AUTHOR CONTRIBUTIONS}

$\mathrm{WR}, \mathrm{XL}, \mathrm{XH}$, and $\mathrm{NH}$ conceived and designed the research. $\mathrm{XL}, \mathrm{ZL}, \mathrm{WR}$ and $\mathrm{NH}$ conducted the experiment. All authors analyzed and interpreted the data. XL and WR wrote the manuscript; all authors discussed and approved the final version.

\section{FUNDING}

This study was jointly funded by the National Key Basic Research Development Program of China (2014CB138804), Natural Science Foundation Committee of Inner Mongolia

\section{REFERENCES}

Aalto, J., Kolari, P., Hari, P., Kerminen, V. M., Schiestl-Aalto, P., Aaltonen, H., et al. (2014). New foliage growth is a significant, unaccounted source for volatiles in boreal evergreen forests. Biogeosciences 11, 1331-1344. doi: 10.5194/bg-111331-2014

Agrawal, A. A. (2002). Herbivory and maternal effects: mechanisms and consequences of transgenerational induced plant resistance. Ecology 83, 3408-3415. doi: 10.1890/0012-9658(2002)083[3408:HAMEMA]2.0.CO;2

Anderson, J. T., Inouye, D. W., Mckinney, A. M., Colautti, R. I., and MitchellOlds, T. (2012). Phenotypic plasticity and adaptive evolution contribute to advancing flowering phenology in response to climate change. Proc. R. Soc. B Biol. Sci. 279, 3843-3852. doi: 10.1098/rspb.2012.1051

Bai, W., Sun, X., Wang, Z., and Li, L. (2009). Nitrogen addition and rhizome severing modify clonal growth and reproductive modes of Leymus chinensis population. Plant Ecol. 205, 13-21. doi: 10.1007/s11258-009-9595-2

Bernacchi, C. J., Morgan, P. B., Ort, D. R., and Long, S. P. (2005). The growth of soybean under free air CO2 enrichment (FACE) stimulates photosynthesis while decreasing in vivo Rubisco capacity. Planta 220, 434-446. doi: 10.1007/ s00425-004-1320-8

Blankenship, R. E. (2002). Molecular Mechanisms of Photosynthesis. Oxford: Blackwell Science. doi: 10.1002/9780470758472

Boonman, A., Prinsen, E., Voesenek, L. A. C. J., and Pons, T. L. (2009). Redundant roles of photoreceptors and cytokinins in regulating photosynthetic acclimation to canopy density. J. Exp. Bot. 60, 1179-1190. doi: 10.1093/jxb/ern364

Conant, R. T., Paustian, K., and Elliott, E. T. (2001). Grassland management and conversion into grassland: effects on soil carbon. Ecol. Appl. 11, 343-355. doi: 10.1890/1051-0761(2001)011[0343:GMACIG]2.0.CO;2

Couso, L. L., and Fernandez, R. J. (2012). Phenotypic plasticity as an index of drought tolerance in three Patagonian steppe grasses. Ann. Bot. 110, 849-857. doi: $10.1093 / \mathrm{aob} / \mathrm{mcs} 147$

Das, A., Das, S., and Mondal, T. K. (2012). Identification of differentially expressed gene profiles in young roots of tea Camellia sinensis (L.) O. Kuntze subjected to drought stress using suppression subtractive hybridization. Plant Mol. Biol. Rep. 30, 1088-1101. doi: 10.1007/s11105-012-0422-x

Day, I. S., Golovkin, M., Palusa, S. G., Link, A., Ali, G. S., Thomas, J., et al. (2012). Interactions of SR45, an SR-like protein, with spliceosomal proteins and an intronic sequence: insights into regulated splicing. Plant J. 71, 936-947. doi: 10.1111/j.1365-313X.2012.05042.x

Demars, B. O. L., Gislason, G. M., Olafsson, J. S., Manson, J. R., Friberg, N., Hood, J. M., et al. (2016). Impact of warming on CO2 emissions from streams
(2016MS0323; 2015ZD02) and Central Non-profit Research Institutes Fundamental Research Funds of China (1610332017005).

\section{ACKNOWLEDGMENTS}

We are sincerely grateful to the editor and two reviewers for their valuable comments on the original version of this manuscript. The authors thank Lei Ji and Yuanfa Meng of Institute of Grassland Research, Chinese Academy of Agricultural Sciences for their help with the field measurements. The long-term project site was maintained by the Inner Mongolia Grassland Ecosystem Research Station.

\section{SUPPLEMENTARY MATERIAL}

The Supplementary Material for this article can be found online at: http://journal.frontiersin.org/article/10.3389/fpls.2017.00419/ full\#supplementary-material

countered by aquatic photosynthesis. Nat. Geosci. 9, 758-761. doi: 10.1038/ ngeo 2807

Desikan, R., Hancock, J. T., Bright, J., Harrison, J., Weir, L., Hooley, R., et al. (2005). A role for ETR1 in hydrogen peroxide signaling in stomatal guard cells. Plant Physiol. 137, 831-834. doi: 10.1104/pp.104.056994

Detling, J. K., Dyer, M. I., and Winn, D. T. (1979). Net photosynthesis, root respiration, and regrowth of Bouteloua gracilis following simulated grazing. Oecologia 41, 127-134. doi: 10.1007/BF00344997

Ellsworth, D. S., Reich, P. B., Naumburg, E. S., Koch, G. W., Kubiske, M. E., and Smith, S. D. (2004). Photosynthesis, carboxylation and leaf nitrogen responses of 16 species to elevated $\mathrm{pCO}(2)$ across four free-air $\mathrm{CO} 2$ enrichment experiments in forest, grassland and desert. Glob. Chang. Biol. 10, 2121-2138. doi: 10.1111/j.1365-2486.2004.00867.x

Escalona, J. M., Flexas, J., and Medrano, H. (1999). Stomatal and non-stomatal limitations of photosynthesis under water stress in field-grown grapevines. Aust. J. Plant Physiol. 26, 421-433. doi: 10.1071/PP99019

Galloway, L. F., and Etterson, J. R. (2007). Transgenerational plasticity is adaptive in the wild. Science 318, 1134-1136. doi: 10.1126/science.1148766

Ge, X.-M., Cai, H.-L., Lei, X., Zhou, X., Yue, M., and He, J.-M. (2015). Heterotrimeric $G$ protein mediates ethylene-induced stomatal closure via hydrogen peroxide synthesis in Arabidopsis. Plant J. 82, 138-150. doi: 10.1111/ tpj.12799

Gonzalez, A. P. R., Chrtek, J., Dobrev, P. I., Dumalasova, V., Fehrer, J., Mraz, P., et al. (2016). Stress-induced memory alters growth of clonal off spring of white clover (Trifolium repens). Am. J. Bot. 103, 1567-1574. doi: 10.3732/ajb. 1500526

Grudzinski, W., Janik, E., Bednarska, J., Welc, R., Zubik, M., Sowinski, K., et al. (2016). Light-driven reconfiguration of a Xanthophyll Violaxanthin in the photosynthetic pigment-protein complex LHCII: a resonance raman study. J. Phys. Chem. B 120, 4373-4382. doi: 10.1021/acs.jpcb.6b0 1641

Heger, T. (2016). Light availability experienced in the field affects ability of following generations to respond to shading in an annual grassland plant. J. Ecol. 104, 1432-1440. doi: 10.1111/1365-2745.12607

Herman, J. J., and Sultan, S. E. (2016). DNA methylation mediates genetic variation for adaptive transgenerational plasticity. Proc. R. Soc. Lond. Ser. B Biol. Sci. 283, 20160988-20160988. doi: 10.1098/rspb.2016.0988

Huang, L., Liang, Z., Suarez, D. L., Wang, Z., Ma, H., Wang, M., et al. (2015). Continuous nitrogen application differentially affects growth, yield, and nitrogen use efficiency of in two saline-sodic soils of Northeastern China. Agron. J. 107, 314-322. doi: 10.2134/agronj14.0250 
Iwasaki, M. (2015). Chromatin resetting mechanisms preventing transgenerational inheritance of epigenetic states. Front. Plant Sci. 6:380. doi: 10.3389/fpls.2015. 00380

Kooke, R., Johannes, F., Wardenaar, R., Becker, F., Etcheverry, M., Colot, V., et al. (2015). Epigenetic basis of morphological variation and phenotypic plasticity in Arabidopsis thaliana. Plant Cell 27, 337-348. doi: 10.1105/tpc.114. 133025

Latzel, V., Gonzalez, A. P. R., and Rosenthal, J. (2016). Epigenetic memory as a basis for intelligent behavior in clonal plants. Front. Plant Sci. 7:1354. doi: $10.3389 /$ fpls.2016.01354

Latzel, V., and Klimesova, J. (2010a). Transgenerational plasticity in clonal plants. Evol. Ecol. 24, 1537-1543. doi: 10.1111/evo.12320

Latzel, V., and Klimesova, J. (2010b). Year-to-year changes in expression of maternal effects in perennial plants. Basic Appl. Ecol. 11, 702-708. doi: 10.1016/ j.baae.2010.09.004

Laureau, C., De Paepe, R., Latouche, G., Moreno-Chac, N. M., Finazzi, G., Kuntz, M., et al. (2013). Plastid terminal oxidase (PTOX) has the potential to act as a safety valve for excess excitation energy in the alpine plant species Ranunculus glacialis L. Plant Cell Environ. 36, 1296-1310. doi: 10.1111/pce. 12059

Lee, U., Rioflorido, I., Hong, S.-W., Larkindale, J., Waters, E. R., and Vierling, E. (2007). The Arabidopsis ClpB/Hsp100 family of proteins: chaperones for stress and chloroplast development. Plant J. 49, 115-127. doi: 10.1111/j.1365-313X. 2006.02940.x

Li, X., Hou, X., Ren, W., Baoyin, T., Liu, Z., Badgery, W., et al. (2016). Long-term effects of mowing on plasticity and allometry of Leymus chinensis in a temperate semi-arid grassland, China. J. Arid Land 8, 899-909. doi: 10.1007/s40333-016$0005-\mathrm{z}$

Li, X., Liu, Z., Wang, Z., Wu, X., Li, X., Hu, J., et al. (2015a). Pathways of Leymus chinensis individual aboveground biomass decline in natural semiarid grassland induced by overgrazing: a study at the plant functional trait scale. PLoS ONE 10:e124443. doi: 10.1371/journal.pone.0124443

Li, X., Wu, Z., Liu, Z., Hou, X., Badgery, W., Guo, H., et al. (2015b). Contrasting effects of long-term grazing and clipping on plant morphological plasticity: evidence from a rhizomatous grass. PLoS ONE 10:e0141055. doi: 10.1371/ journal.pone. 0141055

Li, X.-J., Guo, X., Zhou, Y.-H., Shi, K., Zhou, J., Yu, J.-Q., et al. (2016). Overexpression of a brassinosteroid biosynthetic gene Dwarf enhances photosynthetic capacity through activation of Calvin cycle enzymes in tomato. BMC Plant Biol. 16, 33. doi: 10.1186/s12870-0160715-6

Li, Y., Ren, B., Ding, L., Shen, Q., Peng, S., and Guo, S. (2013). Does chloroplast size influence photosynthetic nitrogen use efficiency? PLOS ONE 8:e62036. doi: 10.1371 /journal.pone. 0062036

Li, Y., Wang, W., Liu, Z., and Jiang, S. (2008). Grazing gradient versus restoration succession of Leymus chinensis (Trin.) Tzvel. Grassland in Inner Mongolia. Restor. Ecol. 16, 572-583. doi: 10.1111/j.1526-100X.2007. 00332.x

Li, Z., Lin, J., Zhang, T., Zhang, N., Mu, C., and Wang, J. (2014). Effects of summer nocturnal warming on biomass production of Leymus chinensis in the Songnen Grassland of China: from bud bank and photosynthetic compensation. J. Agron. Crop Sci. 200, 66-76. doi: 10.1111/jac.12041

Liu, G., and Han, J. (2008). Seedling establishment of wild and cultivated Leymus chinensis (Trin.) Tzvel. under different seeding depths. J. Arid Environ. 72, 279-284. doi: 10.1016/j.jaridenv.2007.06.008

Liu, H., Zang, R., and Chen, H. Y. H. (2016). Effects of grazing on photosynthetic features and soil respiration of rangelands in the Tianshan Mountains of Northwest China. Sci. Rep. 6:30087. doi: 10.1038/srep30087

Liu, Y., Zhang, L., Xu, X., and Niu, H. (2016). Understanding the wide geographic range of a clonal perennial grass: plasticity versus local adaptation. Aob Plants 8:lv141. doi: 10.1093/aobpla/plv141

Liu, Z.-Y., Yang, G.-F., Li, X.-L., Yan, Y.-F., Sun, J., Gao, R., et al. (2016). Autumn dormancy regulates the expression of cas 18 , vsp and corF genes during cold acclimation of lucerne (Medicago sativa L.). Crop Past. Sci. 67, 666-678. doi: $10.1071 / \mathrm{CP} 15289$

Livak, K. J., and Schmittgen, T. D. (2001). Analysis of relative gene expression data using real-time quantitative PCR and the 2(T)(-Delta Delta C) method. Methods 25, 402-408. doi: 10.1006/meth.2001.1262
Mcintyre, P. J., and Strauss, S. Y. (2014). Phenotypic and transgenerational plasticity promote local adaptation to sun and shade environments. Evol. Ecol. 28, 229-246. doi: 10.1007/s10682-013-9670-y

Mcsherry, M. E., and Ritchie, M. E. (2013). Effects of grazing on grassland soil carbon: a global review. Glob. Chang. Biol. 19, 1347-1357. doi: 10.1111/gcb. 12144

N'guessan, M., and Hartnett, D. C. (2011). Differential responses to defoliation frequency in little bluestem (Schizachyrium scoparium) in tallgrass prairie: implications for herbivory tolerance and avoidance. Plant Ecol. 212, 1275-1285. doi: 10.1007/s11258-011-9904-4

Pascal, A. A., Liu, Z., Broess, K., Van Oort, B., Van Amerongen, H., Wang, C., et al. (2005). Molecular basis of photoprotection and control of photosynthetic light-harvesting. Nature 436, 134-137. doi: 10.1038/nature03795

Peng, X., Ma, X., Fan, W., Su, M., Cheng, L., Alam, I., et al. (2011). Improved drought and salt tolerance of Arabidopsis thaliana by transgenic expression of a novel DREB gene from Leymus chinensis. Plant Cell Rep. 30, 1493-1502. doi: 10.1007/s00299-011-1058-2

Rausher, M. D. (2005). Plant evolutionary ecology. New Phytol. 165, 2-5. doi: 10.1111/j.1469-8137.2004.01266.x

Reddy, M. S. S., Dinkins, R., and Collins, G. B. (2002). Overexpression of the Arabidopsis thaliana MinE1 bacterial division inhibitor homologue gene alters chloroplast size and morphology in transgenic Arabidopsis and tobacco plants. Planta 215, 167-176. doi: 10.1007/s00425-001-0728-7

Reich, P. B., Buschena, C., Tjoelker, M. G., Wrage, K., Knops, J., Tilman, D., et al. (2003). Variation in growth rate and ecophysiology among 34 grassland and savanna species under contrasting $\mathrm{N}$ supply: a test of functional group differences. New Phytol. 157, 617-631. doi: 10.1046/j.1469-8137.2003.00703.x

Reynolds, E. S. (1963). The use of lead citrate at high $\mathrm{pH}$ as an electron-opaque stain in electron microscopy. J. Cell Biol. 17, 208-212.

Schönbach, P., Wan, H., Schiborra, A., Gierus, M., Bai, Y., Müller, K., et al. (2009). Short-term management and stocking rate effects of grazing sheep on herbage quality and productivity of Inner Mongolia steppe. Crop Past. Sci. 60, 963-974. doi: 10.1071/CP09048

Shen, H., Wang, S., and Tang, Y. (2013). Grazing alters warming effects on leaf photosynthesis and respiration in Gentiana straminea, an alpine forb species. J. Plant Ecol. 6, 418-427. doi: 10.1093/jpe/rtt010

Tanaka, Y., Nishiyama, Y., and Murata, N. (2000). Acclimation of the photosynthetic machinery to high temperature in Chlamydomonas reinhardtii requires synthesis de novo of proteins encoded by the nuclear and chloroplast genomes. Plant Physiol. 124, 441-449. doi: 10.1104/pp.124.1.441

Teramoto, H., Ono, T.-A., and Minagawa, J. (2001). Identification of Lhcb gene family encoding the light-harvesting Chlorophyll-a/b proteins of photosystem II in Chlamydomonas reinhardtii. Plant Cell Physiol. 42, 849-856. doi: 10.1093/ $\mathrm{pcp} / \mathrm{pce} 115$

Turcotte, M. M., and Levine, J. M. (2016). Phenotypic plasticity and species coexistence. Trends Ecol. Evol. 31, 803-813. doi: 10.1016/j.tree.2016.07.013

von Caemmerer, S., Lawson, T., Oxborough, K., Baker, N. R., Andrews, T. J., and Raines, C. A. (2004). Stomatal conductance does not correlate with photosynthetic capacity in transgenic tobacco with reduced amounts of Rubisco. J. Exp. Bot. 55, 1157-1166. doi: 10.1093/jxb/erh128

Vu, W. T., Chang, P. L., Moriuchi, K. S., and Friesen, M. L. (2015). Genetic variation of transgenerational plasticity of offspring germination in response to salinity stress and the seed transcriptome of Medicago truncatula. BMC Evol. Biol. 15, 59. doi: 10.1186/s12862-015-0322-4

Wang, L., Wang, D., He, Z., Liu, G., and Hodgkinson, K. C. (2010). Mechanisms linking plant species richness to foraging of a large herbivore. J. Appl. Ecol. 47, 868-875. doi: 10.1111/j.1365-2664.2010.01837.x

Wang, Z., Bossdorf, O., Prati, D., Fischer, M., and Van Kleunen, M. (2016). Transgenerational effects of land use on offspring performance and growth in Trifolium repens. Oecologia 180, 409-420. doi: 10.1007/s00442-0153480-6

Whitehead, A., Galvez, F., Zhang, S., Williams, L. M., and Oleksiak, M. F. (2011). Functional genomics of physiological plasticity and local adaptation in Killifish. J. Hered. 102, 499-511. doi: 10.1093/jhered/esq077

Zhao, W., Chen, S.-P., Han, X.-G., and Lin, G.-H. (2009). Effects of longterm grazing on the morphological and functional traits of Leymus chinensis in the semiarid grassland of Inner Mongolia, China. Ecol. Res. 24, 99-108. doi: 10.1371/journal.pone.0141055 
Zheng, S., Ren, H., Li, W., and Lan, Z. (2012). Scale-dependent effects of grazing on plant C: N: P Stoichiometry and linkages to ecosystem functioning in the Inner Mongolia Grassland. PLOS ONE 7:e51750. doi: 10.1371/journal.pone. 0051750

Conflict of Interest Statement: The authors declare that the research was conducted in the absence of any commercial or financial relationships that could be construed as a potential conflict of interest.
Copyright (c) 2017 Ren, Hu, Hou, Zhang, Guo, Liu, Kong, Wu, Wang and $\mathrm{Li}$. This is an open-access article distributed under the terms of the Creative Commons Attribution License (CC BY). The use, distribution or reproduction in other forums is permitted, provided the original author(s) or licensor are credited and that the original publication in this journal is cited, in accordance with accepted academic practice. No use, distribution or reproduction is permitted which does not comply with these terms. 